\title{
Mechanical Buckling Induced Thermoelastic Instability in Frictional Clutches
}

\author{
Heyan Li ${ }^{1,2}$, Mingyang Li ${ }^{1}$, Biao Ma ${ }^{1,2}$, Jikai Liu' ${ }^{1}$ Liang Yu', Huizhu Li ${ }^{1}$ \\ ${ }^{1}$ School of Mechanical Engineering, Beijing Institute of Technology \\ 5 South Zhongguancun Street, Haidian District, Beijing, China \\ ${ }^{2}$ Collaborative Innovation Center of Electric Vehicles in Beijing \\ 5 South Zhongguancun Street, Haidian District, Beijing, China \\ lovheyan@bit.edu.cn; 358853500@qq.com; mabiao@bit.edu.cn; jackylauno1@gmail.com; 2283246298@qq.com; \\ 1617604564@qq.com
}

\begin{abstract}
A multi-disc clutch test bench was set up and sliding experiments were conducted to investigate the relationship between the friction glazed spot distribution and mechanical torsion buckling on frictional components. The buckling deformation model of a separator disc with spline teeth subjected to mechanical torsion is established to compare with the experimental observation. The buckled spline disc provides a certain perturbation frequency during the sliding period. Under this sliding condition, when the relative sliding rubbing speed in frictional clutches exceeds the thermoelastic instability (TEI) speed predicted by Barber and Lee's TEI model, mechanical buckling induces thermoelastic instability (MBTEI). The dangerous sliding speed and perturbation pressure growth rate are obtained in regard to structural parameters, temperatures, abrasion cracks and torques.
\end{abstract}

Keywords: clutch; spline separator discs; mechanical torsion buckling; thermolelastic instability

\section{Introduction}

The study of the clutch is of great interest since clutches are frequently used in the transmission systems of many kinds of vehicles. The temperature of a wet clutch was studied by Li et al. [1] by establishing a 1-D heat transfer model and sliding experiments, from which the wear prediction was made. Some friction and wear experiments were performed by Wei et al. [2] to study the influence of groove surface texture on temperature rise under the condition of dry sliding. Pisaturo and Senatore [3] established a finite element model of a dry clutch to simulate the temperature field of friction components during the engagement process. Zhao et al. [4] established a 3-D model of a dual clutch and a torque transition model to estimate the transmission torques of two clutches in real time. An integrated clutch filling phase control for gearshifts on wet clutch transmissions for heavy-duty vehicles was developed by Meng et al. [5, 6], and the clutch actuator was optimally designed with certain constraints. Wenbin et al. [7, 8] focused on the study of a carbon fabric wet clutch, which is different with traditional materials. The tribological properties were investigated by a carbon fabric wet clutch model established by the modified Reynolds equation and a torque balance equation, and this model was verified by experimental measurements.

During the clutch engagement process, the input energy is large and significant friction heat is generated. This leads to various undesirable effects, such as material transformations, thermal cracking and thermoelastic buckling of friction components, especially under the condition of high local temperatures, and thermal stresses mainly caused by non-uniform surface pressures [9]. The surface pressure distribution characteristics of friction components are therefore important design parameters that significantly influence the performance of the transmission.

The circumferential distributed friction glazed spots (Fig.1) are found on the surfaces of friction components by inspecting a large number of failed clutches. For the phenomenon of circumferential distribution friction glazed spots, investigators explained this problem through thermalelastic instability (TEI) theory [10-18]. The reasonable explanation is that the friction glazed spots were the result of TEI when the sliding speed exceeded the value of the critical TEI velocity, and while there were pressure disturbances on the friction interfaces. Lee et al. [19] established a finite element model of a frictional material and a functionally graded material (FGM) layer to investigate the effect of the volume on frictionally excited TEI, and an optimal FGM volume that exhibits the highest critical speed was found to exist. Other investigators 
[20-23] considered that the thermal buckling deformation of friction components occurred in the sliding process. Timoshenko's bending beam theory was used for the calculation of the critical buckling moment. The study shows that the radial temperature gradient is the main reason for the thermal buckling. A new Timoshenko beam model for large deformation was established by Zhou et al. [24], and the accuracy and efficiency were improved.

From the literature [10-24], the energy of higher order thermal buckling or the phenomenon of many "hot spots" is much higher than the real working condition which leads to the circumferential distributed friction glazed spots shown in Fig.1. However, under the action of mechanical load, there exists the possibility of high order buckling, and a buckled disc will subsequently induce TEI. At present, the research on the buckling deformation of a multi-disc clutch is mainly based on the thermal stresses; while the influence of the mechanical stresses is seldom considered. In this study, we shall extend the TEI analysis to the MBTEI analysis and investigate the stability of spline separator discs subjected to mechanical torsion and the following buckled discs induced TEI problems.
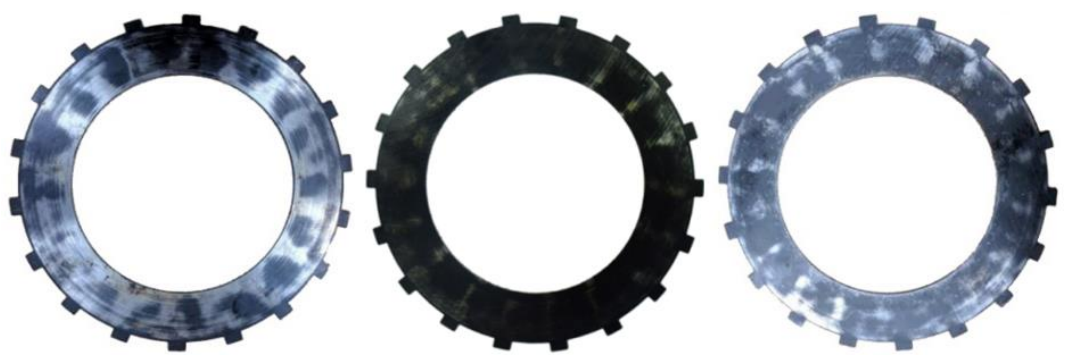

Fig. 1: Pictures of damaged spline separator discs in multi-disc clutches.

\section{Sliding Experiments}

During the clutch engagement process, the fluid oil is pumped into the piston chamber to push the piston axially, overcoming the force of spring separation. The piston pushes friction components moving to eliminate the gaps. The rotation speed difference of the separator discs and friction discs gradually decreases to become synchronous, at which point the clutch completes engagement. Under these working conditions, separator discs are subjected to mechanical torsion by engagements of spline teeth between separator discs and the cylinder liner.

Table 1: Parameters and properties of friction components.

\begin{tabular}{|c|c|c|c|c|}
\hline Material property & $\begin{array}{c}\text { Separator } \\
\text { disc }\end{array}$ & $\begin{array}{c}\text { Friction } \\
\text { lining(Copper) }\end{array}$ & $\begin{array}{c}\text { Friction } \\
\text { lining(Paper) }\end{array}$ & Core plate \\
\hline Young's modulus (Pa) & $210 \mathrm{E} 9$ & $2.27 \mathrm{E} 9$ & $0.1525 \mathrm{E} 9$ & $210 \mathrm{E} 9$ \\
\hline Poisson's radio & 0.29 & 0.27 & 0.12 & 0.29 \\
\hline Thermal expansion coefficient $\left(\mathrm{K}^{-1}\right)$ & $1.27 \mathrm{E}-5$ & $1.21 \mathrm{E}-5$ & $6.3 \mathrm{E}-5$ & $1.27 \mathrm{E}-5$ \\
\hline Thermal conductivity $(\mathrm{W} / \mathrm{mK})$ & 45.9 & 9.3 & 0.22 & 45.9 \\
\hline Specific heat $(\mathrm{J} / \mathrm{KgK})$ & 487 & 460 & 1008 & 487 \\
\hline Thickness $(\mathrm{mm})$ & 2 & 0.6 & 0.6 & 2 \\
\hline Inner radius $(\mathrm{mm})$ & 86 & 86 & 86 & 86 \\
\hline Outer radius $(\mathrm{mm})$ & 125 & 125 & 125 & 125 \\
\hline Pitch radius of separator $(\mathrm{mm})$ & 129 & - & - & 84 \\
\hline
\end{tabular}

\subsection{The Test Bench}

The structure of experimental bench is presented in Fig. 2. The experimental working parameters, geometric parameters, and material parameters of clutch components are shown in Table 1. 


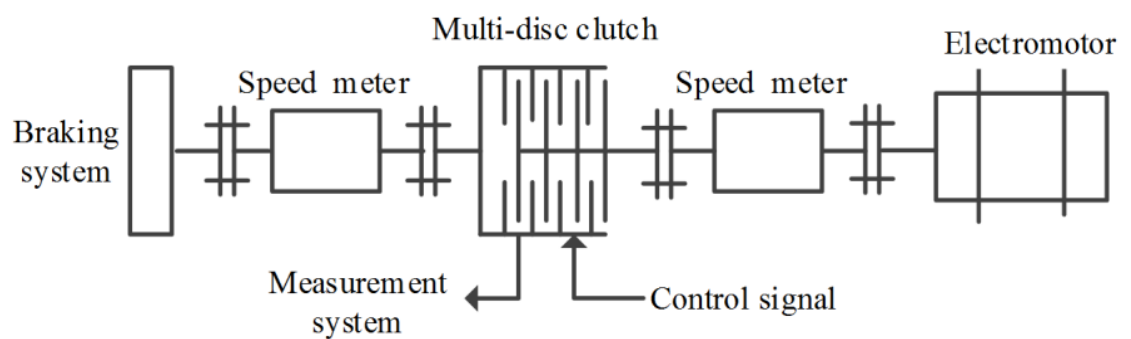

Fig. 2: Test bench of the multi-disc clutch.

\subsection{Experimental Procedure}

Fig. 3 shows the pictures of the same separator disc before and after the long-term multiple engagements of the clutch. In the sliding experiment, the acting pressure is $0.17 \mathrm{MPa}$, relative sliding velocity is $150 / \mathrm{rpm}$, and the sliding time for each engagement cycle is $0.3 \mathrm{~s}$. These sliding conditions are mainly to avoid the influence of thermoelastic instability and high order thermoelastic buckling.

The circumferential distributed friction glazed spots of Fig.3 (b) and Fig.3 (d) are similar with Fig. 1. Side A and B are two sides of the tested separator disc. The frictional traces on these two sides recorded the states of deformation during engagement processes. These spots are highlighted as shown in Fig. 3 (d). The friction glazed spots distribute periodically in circumferential direction which match with the spline teeth very well.
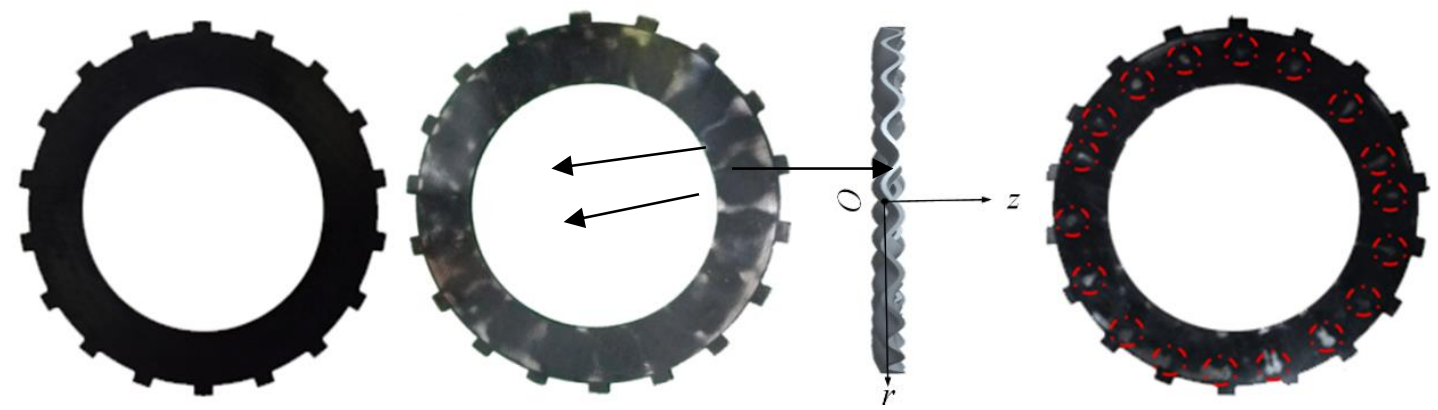

(a) Before the experiment (b) After the experiment (side A) (c) Buckling schematic (d) After the experiment (side B)

Fig. 3: Pictures of subject separator disc.

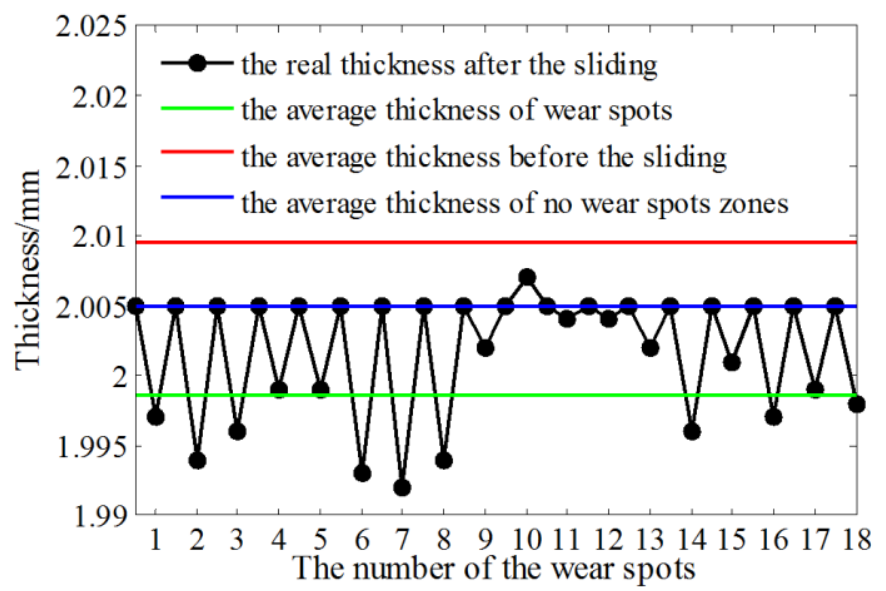

Fig. 4: The thickness measurement of the tested separator disc.

For characterizing the wear condition of the separator disc, the thickness of the separator disc with spline teeth was measured before and after the experiment. The measurement results are shown in Fig. 4. The circumferential friction 
glazed spots are highly correlated with the spline teeth distribution of the separator disc. When the sliding process is over, the frictional glazed spots generate on the surface of the separator disc.

\section{Buckling Analysis of Separator Disc with Spline Teeth}

As shown in Fig. 3, the phenomenon in Fig. 1 is successfully recreated by long-term multiple engagements of clutch. The energy of higher order thermal buckling or the phenomenon of so many "hot spots" is much higher than this experimental working condition. The frictional spots are clear and not overlayed on both side A and side B, which are different with the "hot spots" of TEI. Therefore, the possibility exists of high order buckling under the action of mechanical torsion load.

The bending action could be recovered when the interference force is removed. This phenomenon is called buckling [25]. Under the condition of mechanical torsion, the separator disc will be buckled and the possible deformation processes of the separator disc are proposed, as shown in Fig. 5. The buckling deformation processes of the separator disc can be divided into three stages: A, B and C. Stage A is a 'flat state', where the separator disc stays flat until the mechanical torque exceeds the critical buckling value. Then the separator disc turns into an unstable stage. With the effects of normal pressure disturbance, the disc will be buckled as waves in the circumferential direction, as shown in stage B. If the mechanical loads don't exceed the elastic limit, the disc will recover to flat after the load is removed. However, friction glazed spots will remain (stage C).

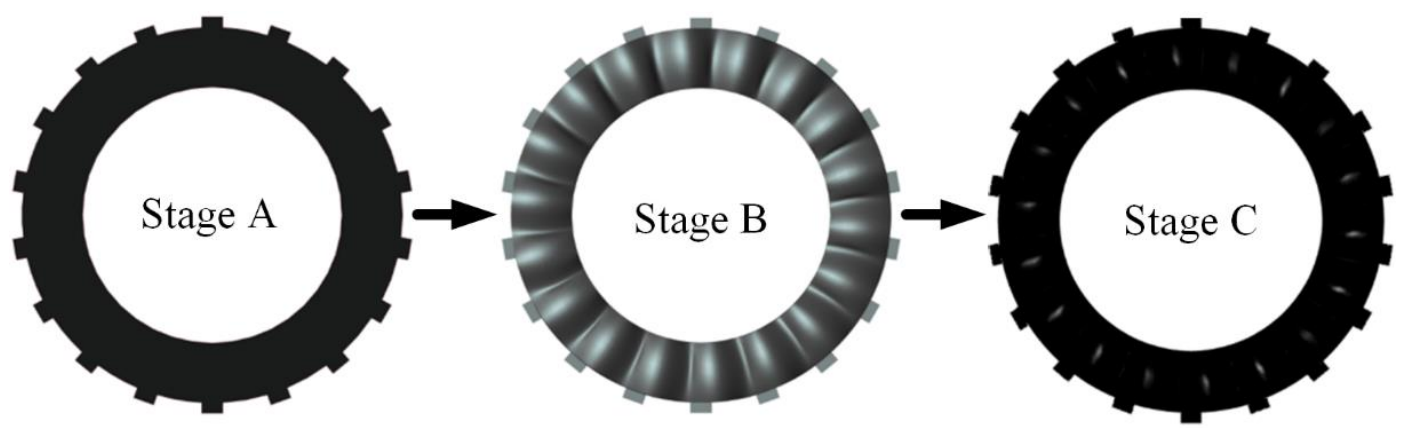

Fig. 5: Deformation processes of separator disc with spline teeth.

\section{Influences of Mechanical Buckling on TEI}

The disc with spline teeth buckled by mechanical torsion provides a certain perturbation frequency which affects the stability of the friction system, as shown in Fig. 5. The frictional heart flux generated at the contact interface of a sliding system is proportional to the contact pressure. Therefore, if some non-uniformity in pressure distribution across the surface occurs, the areas where the pressure is higher experience a higher temperature increase. This is turn causes greater local thermal expansion and thereby leads to further local pressure increase.

\subsection{Model and Formulation of MBTEI}

As the deformation of the buckled disc is typically anti-symmetric, the theoretical model used in this paper is the traditional anti-symmetric TEI model. This in-plane sliding 2-D TEI mode was studied by Lee [12], Jang [13] and Lee [14] based on the TEI theory of Baber [10-11]. In these studies, the friction coefficient is considered a constant parameter. The perturbed pressure superimposes a cosine perturbation with perturbation frequency $\lambda$ at the sliding interface and has the form

$$
\begin{gathered}
P_{\lambda}=p_{0} \cos (\lambda x) \exp (b t) \\
\lambda=\frac{2 \pi}{l_{w}}
\end{gathered}
$$


where $p_{0}$ is the initial perturbed pressure, $l_{w}$ is the wavelength of pressure perturbation, $\lambda$ is the perturbation frequency, and $b$ is the perturbation pressure growth rate, where $b$ can be (1) $b<0$-stable perturbation, (2) $b>0$-unstable perturbation, and (3) $b=0$-threshold of instability, for which the critical speed $V_{c r}$ is determined.

\subsection{Results and Analysis}

Copper-based friction discs are more commonly used in most multi-disc clutches than paper-based discs. The critical speed $V_{c r}$ responds to $\mathrm{Cu}$-Steel friction pairs, as shown in Fig. 6. The parameters used in this simulation calculation are listed in Table 1. Cu-Steel friction pairs are usually working at the TEI state without obvious damage. The results agree well with Zagrodzki's [16] conclusion that many sliding systems, like transmission clutches or brakes, operate instantaneously at a high speed that significantly exceeds the critical speed $V_{c r}$. This indicates that thermolelastic instability does not lead to the failure of the friction components directly. In this case, the speed directly responds to damage of the friction components is of great interest. Using TEI critical speed $V_{\text {cr }}$ as the only parameter to determine the safety of the sliding system is not comprehensive. As a supplement, the yielding speed $V_{d}$ is defined as the speed which could lead to the contact pressure exceeding the material yield strength $\left[\sigma_{s}\right]$. When the frictional system is unstable, namely $V>V_{c r}$ and $b>0$, the disturbing pressure $P_{\lambda}$ will become much greater than non-disturbing pressure $P_{u}$, then $P_{u}$ can be neglected and the contact pressure $P$ has the form $\mathrm{P} \approx P_{\lambda}$. When the initial perturbed pressure $p_{0}$ is $1 \mathrm{pa}, \lambda=180 / \mathrm{Hz}$, sliding time $t$ is $0.2 \mathrm{~s}$, the critical damage pressure growth rate $\mathrm{b}_{\mathrm{cr}}$ (Table 2) and $V_{d}$ can be obtained by Eqs.(1) and (3). The relationship of $b, b_{c r}, V$ and $V_{d}$, shown in Fig. 7, is investigated by the MBTEI model and Eqs. (3-5), meanwhile the maximum pressure growth rate $\mathrm{b}_{\max }$ and $V_{d}$ are listed in Table 3.

$$
\begin{aligned}
& \left\{\begin{array}{c}
P=P_{u}+P_{\lambda} \geq\left[\sigma_{s}\right] \\
V_{d}=f(P) \\
b_{c r}=g\left(\mathrm{~V}_{d}\right)
\end{array}\right. \\
& \mathbf{M S}=0 \\
& |\mathbf{M}|=0
\end{aligned}
$$

where $\mathbf{M}=\left[\mathbf{M}_{1}(V, c, b, \lambda), \mathbf{M}_{2}(V, c, b, \lambda) \ldots \mathbf{M}_{\mathrm{i}}(V, c, b, \lambda)\right]$ is system parameter matrix of TEI and $\mathbf{S}$ is the independent parameter vector of system stability. $P$ is the contact pressure, $P_{u}$ is the non-disturbing pressure and $b_{c r}$ is the critical damage pressure growth rate.

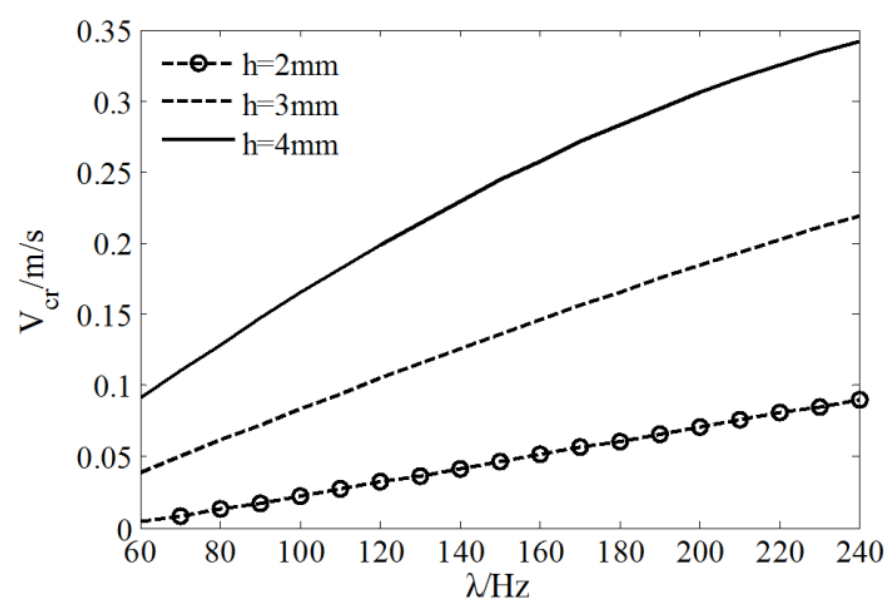

Fig. 6: Critical speed $V_{c r}$ responds to $\mathrm{Cu}-\mathrm{Steel}$ friction pairs. 


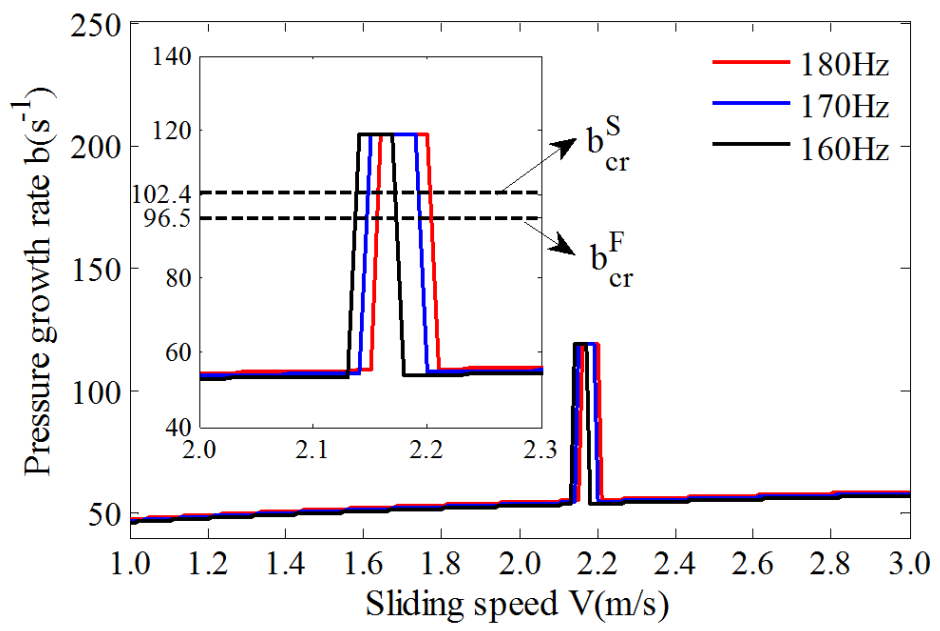

Fig. 7: The pressure growth rate $b$.

Table 2: The critical damage pressure growth rate $b_{\mathrm{cr}}$.

\begin{tabular}{|c|c|c|}
\hline Material & \multicolumn{2}{|c|}{$\left[\sigma_{\mathrm{s}}\right] / \mathrm{MPa} \quad b_{c r}\left(\mathrm{~s}^{-1}\right)$} \\
\hline Separator disc & $785 \mathrm{MPa}$ & $b^{S}{ }_{c r}=102.4$ \\
\hline Friction disc & $250 \mathrm{MPa}$ & $b^{F}{ }_{c r}=96.5$ \\
\hline
\end{tabular}

Table 3: $V_{d}$ and $b_{\max }$.

\begin{tabular}{|c|c|c|c|}
\hline \multirow{2}{*}{ Parameters } & \multicolumn{3}{|c|}{ perturbation frequency $\lambda / \mathrm{Hz}$} \\
\cline { 2 - 4 } & 160 & 170 & 180 \\
\hline$b_{\max }\left(\mathrm{s}^{-1}\right)$ & 118.77 & 118.87 & 118.96 \\
\hline$V_{d}(\mathrm{~m} / \mathrm{s})$ & $2.14-2.17$ & $2.15-2.19$ & $2.16-2.20$ \\
\hline
\end{tabular}

The curves, shown in Fig. 7, indicate that pressure growth rate $b$ has a peak, and the peak is 3 times greater than the average value. In general, except the peaks, $b$ increases with the increasing of $V$. When $V$ changes from $1 \mathrm{~m} / \mathrm{s}$ to $3 \mathrm{~m} / \mathrm{s}, b$ increases by $73 \%$. As shown in Table $3, V_{d}$ varies positively with the increasing of $\lambda$, when the perturbation frequency $\lambda$ is $180 \mathrm{~Hz}$, calculated by Eq. 2 under the experimental condition 3, the yielding speed $V_{d}$ is $2.16-2.20 \mathrm{~m} / \mathrm{s}$ which is 44 times greater than the TEI critical speed $\left(V_{c r}=0.05 \mathrm{~m} / \mathrm{s}\right)$. At this sliding speed, the pressure growth rate $b$ exceeds the critical damage pressure growth rate $b_{c r}$. The contact pressure then exceeds the material yield strength and leads to damage of the discs.

The verification experiments were conducted by using the same multi-disc clutch experimental bench. However, the relative sliding linear speed is increased to $2.16-2.20 \mathrm{~m} / \mathrm{s}$ which is equivalent to the dangerous speed shown in Table 3 . After the long-term multiple engagements of the clutch, the pictures of the tested separator disc are shown in Fig. 8. As shown, there are several circular cracks on the surface of the disc which indicate that the disc is damaged under this sliding speed. However, when the sliding speed is smaller than $V_{d}$, the circular cracks will not come out even under the same time of sliding, as shown in Fig. 3 (b). 


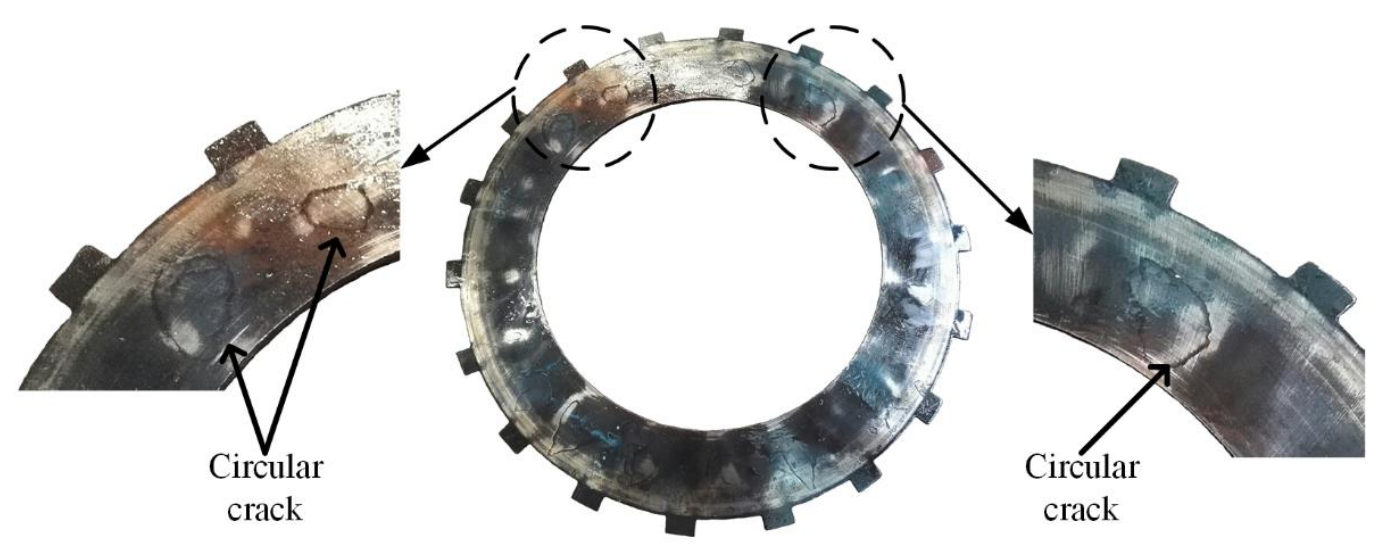

Fig. 8: Pictures of a separator disc after a long period of intermittent sliding.

\section{Conclusion}

A new kind of sliding multi-disc clutch experiment was designed to investigate the mechanism for circumferentially distributed friction glazed spots on the surface of separator discs with spline teeth in multi-disc clutches. The frictional glazed spots distributed periodically in a circumferential direction on the surface of separator discs can be caused by mechanical torsion when the moment exceeds $M_{c r}$. This buckling deformation makes the actual contact area become smaller, thereby increasing the contact pressure and the degree of wear. When the sliding process is over, the frictional glazed spots generate on the surface of the separator disc.

The disc with spline teeth buckled by mechanical torsion provides a certain perturbation frequency which affects TEI critical speed $V_{c r}$ and pressure growth rate $b$; the perturbation frequency $\lambda$ can be assumed to be fixed with the separator disc. So under these conditions, the sliding speed can be expressed as $\mathrm{V} \approx \mathrm{c}_{1}$, and the nonlinear transcendental equations can be simplified by this assumption; in addition, the calculation efficiency is greatly improved.

Under the condition of MBTEI, the dangerous sliding speed $V_{d}$ and the perturbation pressure growth rate $b$ are calculated to characterize the stability of the friction system as supplements of TEI critical speed $V_{c r}$. The results show that the pressure growth rate $b$ has a peak, and the value of the peak varies with changing $\lambda$ and sliding speed. When the buckled frictional discs are sliding at $V_{d}$, the perturbation pressure growth rate $b$ reaches the peak, then the perturbation pressure increases quickly and leads to the damage of discs.

\section{Acknowledgements}

The research described in this paper was financially supported by the Natural Science Foundation of China (Grant No.51575042).

\section{References}

[1] M. Li, M. M. Khonsari, N. Lingesten, P. Marklund, D. M. C. McCarthy, J. Lundin, "Model validation and uncertainty analysis in the wear prediction of a wet clutch," Wear, vol. 364, pp. 112-12, 2016.

[2] W. Wu, T. Shao, and G. Chen, "Influence of groove surface texture on temperature rise under dry sliding friction," Sci. China Technol. Sc., vol. 59, no. 2, pp. 183-190, 2016.

[3] M. Pisaturo, and A. Senatore, "Simulation of engagement control in automotive dry-clutch and temperature field through finite element model," Appl. Therm. Eng., vol. 93, pp. 958-966, 2016.

[4] Z. Zhao, L. He, Y. Yang, C. Wu, X. Li and J. K. Hedrick, "Estimation of torque transmitted by clutch during shifting process for dry dual clutch transmission," Mech. Syst. Siganl Pr., vol. 75, pp. 413-433, 2016.

[5] F. Meng, H. Chen, T. Zhang and X. Zhu, "Clutch fill control of an automatic transmission for heavy-duty vehicle applications," Mech. Syst. Siganl Pr., vol. 64, pp. 16-28, 2016.

[6] F. Meng, P. Shi, H. R. Karimi and H. Zhang, "Optimal design of a electro-hydraulic valve for heavy-duty vehicle clutch actuator with certain constraints," Mech. Syst. Siganl Pr., vol. 68, pp. 491-503, 2016.

[7] L. Wenbin, H. Jianfeng, F. Jie, C. Liyun, Y. Chunyan and W. Wenjing, "Simulation of the engagement of carbon fabric wet clutch: Analytical and experimental comparison," Tribol. Int., vol. 90, pp. 502-508, 2015. 
[8] L. Wenbin, H. Jianfeng, F. Jie, L. Zhenhai, C. Liyun and Y. Chunyan, "Study on tribological properties as function of operating conditions for carbon fabric wet clutch," Tribol. Int., vol. 94, pp. 428-436, 2016.

[9] P. Marklund, F. Sahlin and R. Larsson, "Modeling and simulation of thermal effects in wet clutches operating under boundary lubrication conditions," P. I. Mech. Eng. J-J Eng., vol. 223, pp. 1129-1141, 2009.

[10] J. R. Barber, "The influence of thermal expansion on the friction and wear process," Wear, vol. 10, pp. 155-159, 1967.

[11] J. R. Barber, "Thermoelastic instabilities in the sliding of conforming solids," P. Roy. Soc. A-Math Phy., vol. 312, pp. 381-394, 1969.

[12] K. Lee, J. R. Barber, "Frictionally excited thermoelastic instability in automotive disk brakes," J. Tribol-T. ASME, vol. 115, pp. 607-614, 1993.

[13] J. Y. Jang and M. M. Khonsari, "On the formation of hot spots in wet clutch systems," J. Tribol-T. ASME., vol. 124, pp. 336-345, 2002.

[14] S. W. Lee and Y. H. Jang, "Effect of functionally graded material on frictionally excited thermoelastic instability," Wear, vol. 266, pp. 139-146, 2009.

[15] J. Zhao, B. Ma, H. Li and Y. Yi, "The effect of lubrication film thickness on thermoelastic instablility under fluid lubricating condition," Wear, vol. 303, pp. 146-153, 2009.

[16] P. Zagrodzki, "Analysis of thermomechanical phenomena in multidisc clutches and brakes," Wear. vol. 140, pp. 291-308, 1990.

[17] P. Zagrodzki, "Themoelastic instability in friction clutches and brakes-transient modal analysis revealing mechanisms of excitation of unstable modes," Int. J. Solids Struct., vol. 46, pp. 2463-2476, 2009.

[18] Y. Yi, "Finite Element Analysis of Thermoelastic Dynamic Instability Involving Fricional Heating," J. Tribol-T. ASME., vol. 128, pp. 718-725, 2006.

[19] H. Lee and Y.H. Jang, "Effect of the volume of a functionally grated material layer on frictionally excited thermoelastic instability," Tribol. Int., vol. 49, pp. 103-109, 2012.

[20] N. Audebert, J.R. Barber and P. Zagrodzki, "Buckling of automatic transmission clutch plates due to thermoelastic plastic residual stresses" J. Therm. Stresses, vol. 21, pp. 309-326, 1998.

[21] C. Ma, "Thermal buckling of automotive brake discs," PhD dissertation, University of Michigan, Michigan, USA.

[22] M.M.Ghomshei and V. Abbasi, "Thermal buckling analysis of annular FGM plate having variable thickness under thermal load of arbitrary distribution by finite element method," J. Mech. Sci. Technol., vol. 27, pp. 1031-1039, 2013.

[23] C. Xiong. B. Ma and H. Li, "Experimental study and thermal analysis on the buckling of friction components in multi-disc clutch," J. Therm. Stresses, vol. 38, pp. 1325-1345, 2015.

[24] G. Zhou, R. Hui, W. Zhao, C. Wang and B. Xu, "A new Timoshenko beam model for simulation of mechanical system with large deformation,” Sci. China Technol. Sc., vol. 59, no. 11, pp. 1639-1645, 2016.

[25] J. R. Barber, Intermediate mechanics of materials. New York: Springer, 2000.

[26] S. P. Timoshenko and J. M. Gere, Theory of Elastic Stability. New York: Dover Publications Inc, 1961.

[27] D. A. Pacey, "Modeling heat transfer in a wet clutch," Ph.D. Dissertation, Kansas State University, Kansas, USA.

[28] J. Zhao, "Research on the thermoelastic instability of shifting clutches in the process of engagement," Ph.D. dissertation, Beijing Institute of Technology, Beijing, China. 